\title{
Report of ectopic kidney in thorax with bilateral vesicular uretral reflux
}

\author{
Hashem Mahmoudzade', Ahmad Ali Nikibakhsh ${ }^{r}$
}

Received: 20 Feb, 2017; Accepted: 25 Apr, 2017

\begin{abstract}
A-6 - months old infant was assessed with urinary tract infection. In the abdominal sonography left kidney was absent. In radiology report single kidney noted. DTPA SCAN was requested for evaluation of moderate hydronephrosis of the right kidney and ectopic in the chest area was seen. Then VCUG was requested for further evaluation that showed bilateral reflux in urinary system. The mass was seen in CXR that related to an ectopic kidney.
\end{abstract}

Keywords: ectopic kidney, lung, radioisotope scan, hydronephrosis

Address: Urmia University of Medical Sciences, Shahid Motahari Hospital, Urmia, Iran

Tel: (+98) 9143458715

Email: mahmoudzadeh_ha@yahoo.com

\section{Introduction}

Abnormalities of the urinary system includes $10 \%$ of the born population (1). One of the most common disorders is ectopic kidney. Commonly, ectopic kidneys places in pelvis, abdomen and iliac fossa (2). Kidney's placement in the chest is a very rare phenomenon which is due to the further advancement of renal pelvis to the chest and happens before apertureclose (3). The ectopic kidney is generally rare and is observed 1 in 1,000 births that less than 1 in 10,000 kidneys is misplaced in Thoracic (4) (Actually about one in ten million births). Given that the reflux have not been reported in the majority of reports, this case is different from other reports due to the misplaced kidney in the lungs and without reflux which is rare.
This is mostly due to lung mass, failure to see kidney in the abdominal area and accidental observations with nuclear medicine (5).

\section{Case report}

A 6-month old infant referred due to a fever a week ago and preliminary analysis showed leukocyturia and nitrites $2+$ in urine and bacteriuria with positive E.coli with more than $10^{5}$ colonies in urine cultures. Ultrasound was reported existence of a right kidney with moderate hydronephrosis (AP pelvis diameter of 13 $\mathrm{mm})$. DTPA and VCUG scan were requested for the patient to understand the characteristics of obstruction.

Hydronephrosis of the right kidney was without obstruction in DTPA scan (Figure 1).

\footnotetext{
${ }^{1}$ Associate Professor, Pediatric Nephrology, Urmia University of Medical Sciences, Urmia, Iran (Corresponding Author)

${ }^{2}$ Professor of Pediatric Nephrology, Urmia University of Medical Sciences, Urmia, Iran
} 


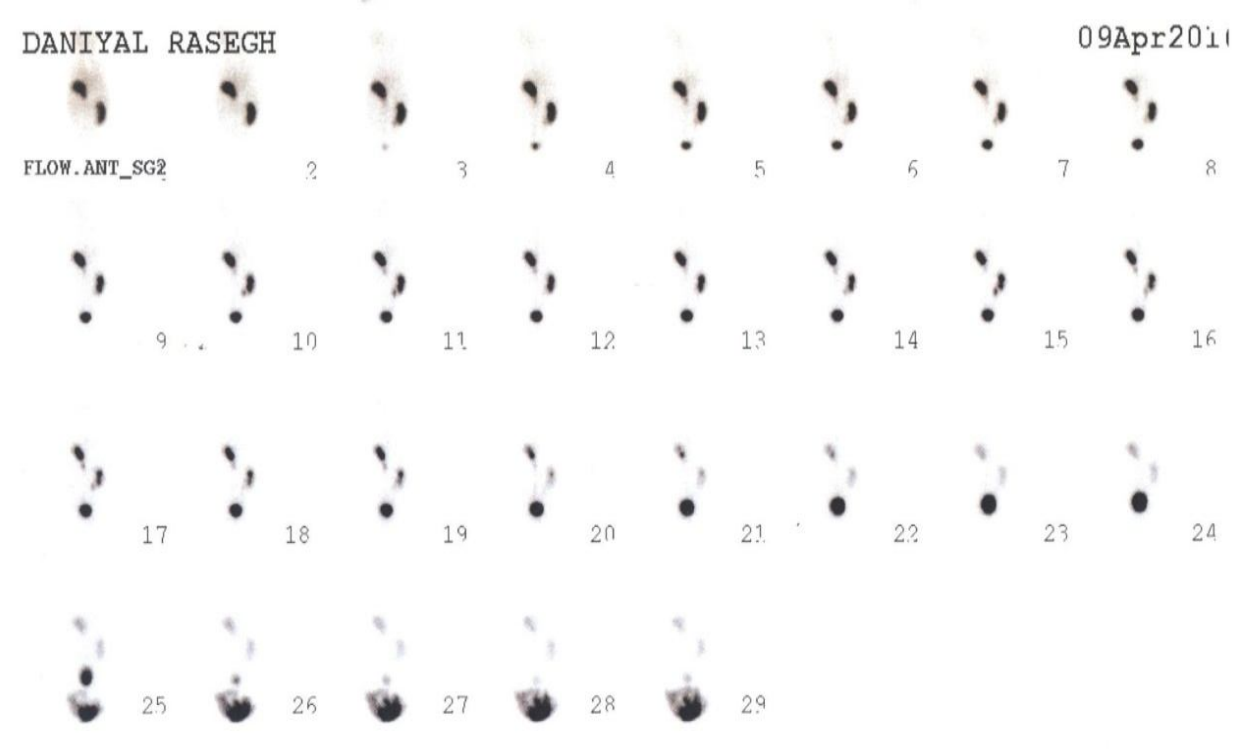

Figure 1

The other kidney was reported as intra thoracic in stomach. Bilateral reflux grade III was detected in VCUG (Figure 2).

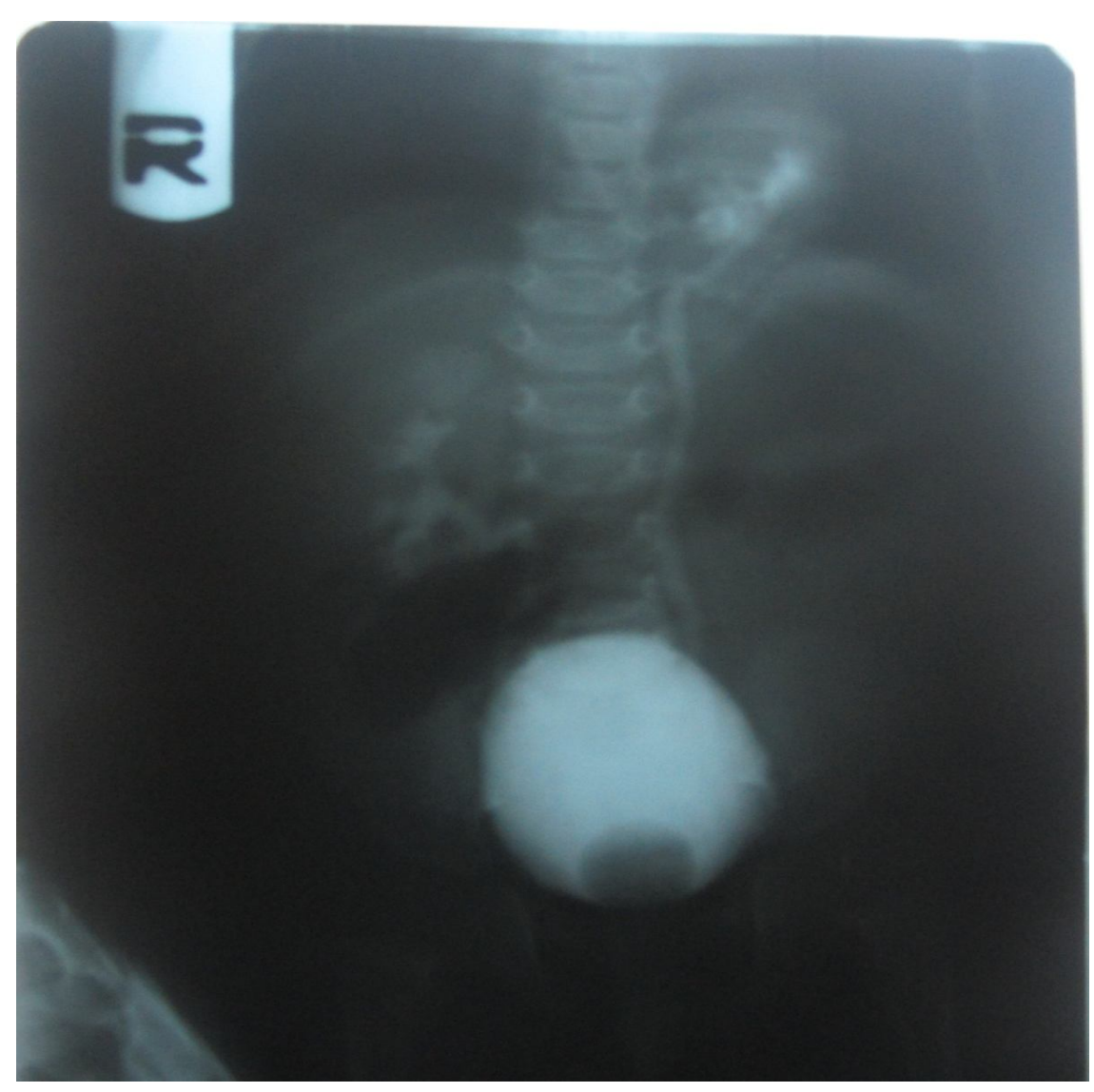

Figure 2

A mass was observed in the heart to the left in CXR (Figure 3) 


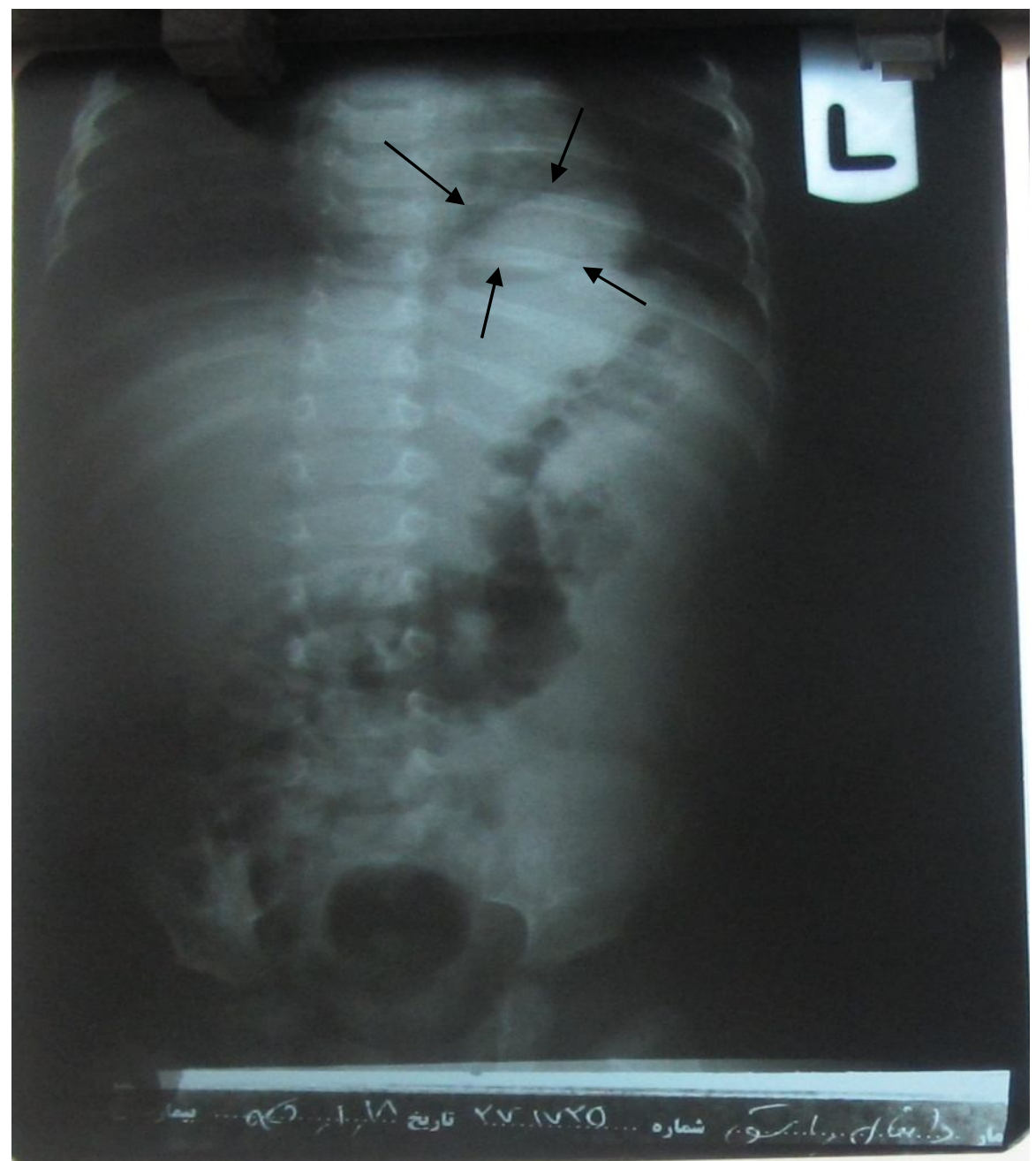

Figure 3

And CT scan also reported a kidney in the thoracic. (Figure 4)

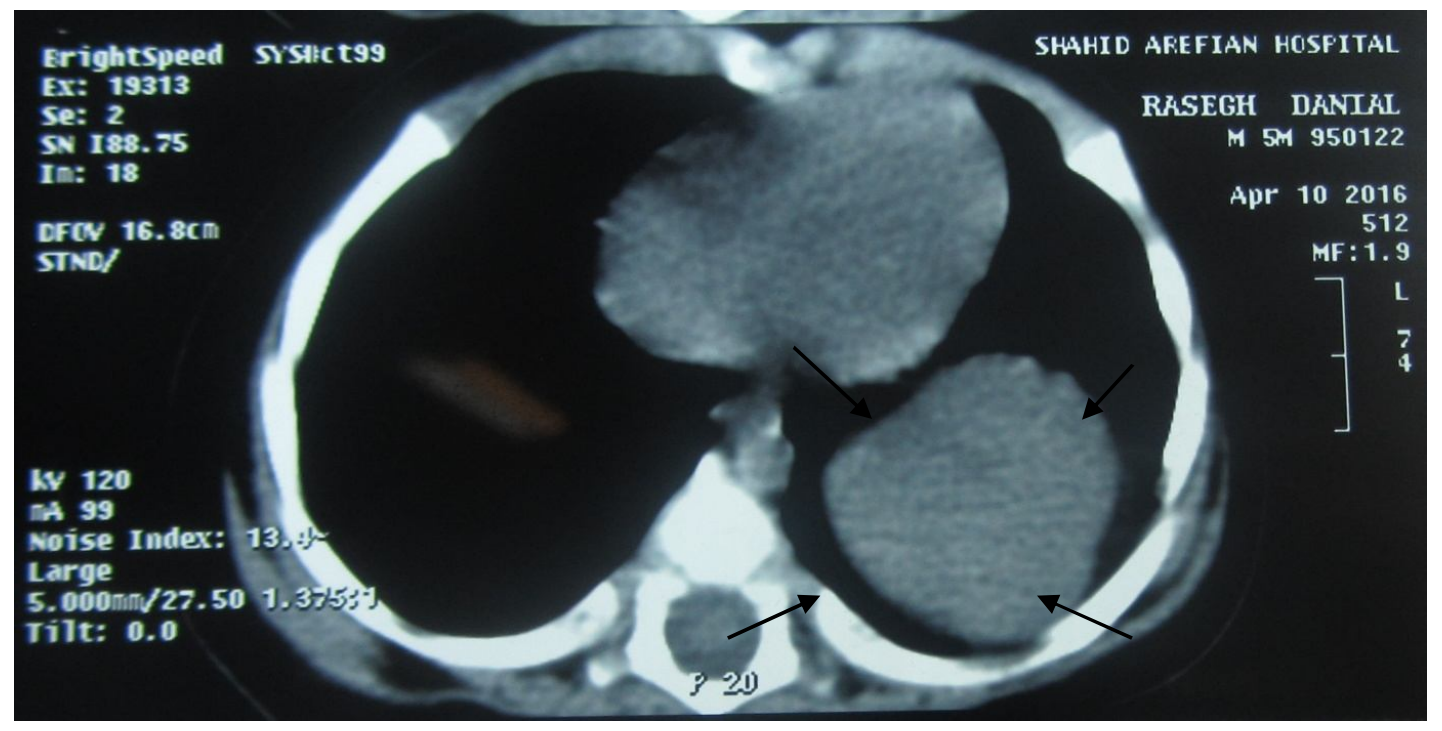

Figure 4 


\section{Discussion}

Ectopic kidney usually can be seen in the pelvis or abdomen or iliac fossa. The most common location of ectopic kidney is in the pelvis and the chest is rarest location (6). The reasons for ectopic kidney in thorax are not well-known, but appears to be due to the rapid movement of kidney from the bottom to the top at embryonic period before the aperture slots are closed (7). If thoracic kidneys are asymptomatic with normal function without clinical symptoms in the lungs (8), the patient can be diagnosed by X-rays (IVP) or nuclear

\section{References}

1. Queisser-Luft A, Stolz G, Wiesel A, Schlaefer K, Spranger J. Malformations in newborn: results based on 30940 infants and fetuses from the Mainz congenital birth defect monitoring system (1990-1998). Arch Gyhe obst 2002;266(3):163-7.

2. Arslan H, Aydogan C, Orcen C, GonIllu E. A rare case: Congenital thoracic ectopic kidney with diaphragmatic eventration. J Pak Med Assoc 2016;66(3):339-41.

3. Magak P, King CH, Ireri E, Kadzo H, Ouma JH, Muchiri EM. High prevalence of ectopic kidney in Coast Province, Kenya. Trop Med Int Health 2004;9(5):595600.

4. Natarajan A, Agrawal A, Purandare N, Shah S, Rangarajan V. Rare case of thoracic kidney detected by medicine or even VCUG that it was identified through nuclear medicine and VCUG by reflux in our patient. In general, pelvic kidney may have reflux in $10 \%$ of cases, but thoracic kidney with reflux was rarely observed in multiple studies. Our patient had bilateral reflux. Our patient had no disorder in other organs. It seems to be a form of isolated and alone disorder without other abnormalities. In case of observing a mass in the lungs, especially in children, it is better to have less probability of cancer. We have to think about ectopic kidney.

renal scintigraphy. Indian J Nucl Med 2016;31(3):21921.

5. Khoshchehreh M, Paknejad O, Bakhshayesh-Karam M, Pazoki M. Thoracic Kidney: Extremely Rare State of Aberrant Kidney. Case Rep Urol 2015;2015:672628.

6. Aydin HI, Sarici SU, Alpay F, Gökçay E. Thoracic ectopic kidney in a child: a case report. Turk J Pediatr 2000;42(3):253-5.

7. Liddell RM, Rosenbaum DM, Blumhagen JD. Delayed radiologic appearance of bilateral thoracic ectopic kidneys. AJR Am J Roentgenol 1989;152(1):120-2.

Sheih C-P, Liu M-B, Hung C-S, Yang K-H, Chen W-Y, Lin C-Y. Renal abnormalities in schoolchildren. Pediatrics 1989;84(6):1086-90. 